\title{
The All-pay Auction with Non-monotonic Payoff
}

\author{
Subhasish M. Chowdhury* \\ School of Economics, Centre for Behavioural and Experimental Social Science, and Centre for \\ Competition Policy, University of East Anglia, Norwich NR4 7TJ, UK. \\ Email: s.modak-chowdhury@uea.ac.uk
}

\begin{abstract}
We model innovation contests as an all-pay auction in which it is possible not to achieve successful innovation despite costly R\&D investments, and as a result, there is no winner. In such a case the winning payoff turns out to be non-monotonic in own bid. We derive the sufficient conditions for the existence of pure strategy equilibria, and fully characterize the non-degenerate mixed strategy equilibrium. In the mixed strategy equilibrium, the support of the low-value bidder is not continuous, and both the high-value and the low-value bidders place an atom in the (distinct) lower bound of their respective support. Under symmetric valuation, both bidders place an atom at zero. These results can explain why we do not observe very low quality innovation in real life, or why even symmetric firms may stay out of an innovation contest.
\end{abstract}

JEL Classifications: C72, 74, D44, O30

Keywords: Innovation, All-pay auction, No-win, Non-monotonicity

* An earlier version of this study was circulated in 2009. I appreciate the useful comments of two anonymous referees, Yeon-Koo Che, Dan Kovenock, Stephen Martin, Bill Novshek, Roman Sheremeta, Iryna Topolyan, the participants at the 'Contests and Innovation' workshop in Anchorage, $20^{\text {th }}$ Game Theory Festival at SUNYSB, Midwest Economic Theory meetings at Iowa, $10^{\text {th }}$ SAET Conference in Singapore, and the seminar participants at the Universities of Cincinnati, East Anglia, Monash, Purdue, and Yonsei. Any remaining errors are mine alone. 


\section{Introduction}

In an innovation contest, firms make costly $R \& D$ investments to innovate a new product or process, and usually the highest quality innovation wins a patent or helps the owner firm to gain a high market share. This procedure matches closely with a contest in which players have the opportunity to make sunk investment of scarce resources in order to win prize(s). In specific, due to its cutthroat nature, innovation tournaments and patent races can be modeled as an all-pay auction - where bidders simultaneously bid for prize(s) and pay their bids irrespective of the outcome. Because of its wide applications to electoral contests, rent-seeking activities, legal disputes, in addition to patent races and innovation tournaments, the all-pay auction has been a popular research tool. The equilibrium under complete information for the first-price all-pay auction, in which a single prize is awarded with certainty to the highest bidder, is fully characterized by Baye et al. (1996). ${ }^{1}$

Modeling an innovation contest as a standard all-pay auction, however, has its limitations since it cannot explain certain phenomena in innovation. For example, non-participation of symmetric players, or non-observability of very low quality innovation in a patent race cannot be explained with a standard all-pay auction model. Furthermore, the intrinsic nature of an innovation process incorporates two specific features that a standard all-pay auction fails to capture. First, there are two types of uncertainties in an innovation process (Loury, 1979): (i) a competitor may make a successful innovation before one does himself; and (ii) despite costly investments in R\&D, the innovation may fail to be successful. A standard all-pay auction cannot model the latter type of risk. Second, the value of the prize in the innovation may depend on the level of investment. One needs to apply an all-pay auction model with bid-dependent prize value in such situations.

In this study, we introduce an all-pay auction with complete information that incorporates these features. This model introduces the possibility that even the highest bid, if it is below a certain random threshold, may fail to win the prize and the prize value becomes concave in own bid. This, in turn, results in a non-monotonic winning payoff in own bid. We characterize all Pure Strategy Nash Equilibria (PSNE) and Mixed Strategy Nash Equilibrium (MSNE) under this structure. This is one of the first attempts to characterize equilibria for all-pay auctions in which the payoff unction

\footnotetext{
${ }^{1}$ Baye et al. (1996) show that if there are unique bidders with highest and second-highest value for the prize, then a there exists no PSNE, but a symmetric MSNE exists. For more than two second-highest value bidders, a continuum of asymmetric MSNE exists. See also Baye et al. (1993) and Hilman and Riley (1989).
} 
is non-monotonic in own bid. The equilibrium results explain some of the phenomena in the innovation process that a standard all-pay auction model with monotonic payoff cannot explain.

These two features (no-win, and bid dependent prize) discussed above are very common in various situations including and beyond the innovation process. A prominent example of the nowin case is a successful technological innovation that is not marketable. After making costly investments, products such as jetpack and teleportation machine were invented in 1961 and in 1993. But due to non-marketability issues none of these returned any profit to the inventors (Wilson, 2007). In another example, firms may expend costly resources to create a product prototype and submit the same for a procurement auction (Che and Gale, 2003). However, the demand-side may not like any of the prototypes and reject all. Furthermore, interest groups may lobby a government to influence the details of regulations (Baye et al., 1993), yet the government may issue regulations that do not favor any special interest group. Finally, several male may compete to court a female. But, despite their effort, she might decide to choose none. ${ }^{2}$

Similarly, there are numerous practical situations when the valuation of the prize in an all-pay auction is affected by the bid. An example of this is the dependence of a patent's value on the corresponding $R \& D$ expenditures. A firm may earn a patent on a particular product if it can innovate that product before its rivals do. But, at the same time, the firm's expected payoffs from the patent is greater if the product is of higher quality due to a higher volume of R\&D expenditure. ${ }^{3}$ Another example is the relationship between the size of the gains by lobbyists and the corresponding lobbying expenses in rent-seeking. A lobby group might succeed in influencing government decision by making more lobbying expenditure than its rivals; and at the same time the degree of influence might well be affected by the amount of lobbying expenditure. An example of this type in rent seeking (Tullock, 1980) is given by Amegashie (1999). Other examples include singing contests (e.g. American Idol) and business plan competitions. The best singer or business proposal wins the contest and at the same time a better performance gives a higher valued contract to the winner. For similar examples in sports and labor, see Bos and Ranger (2014).

\footnotetext{
${ }^{2}$ See Sozou and Seymour (2005) for failure in courtship efforts (giving gifts). Even animals expend a variety of costly irreversible effort in terms of courtship dance, songs, use of pheromone, and physical contest with other males etc. with the intention of mating a particular female (Daly, 1978 and Bastock, 2007). However, in the post courtship period, it is possible that none from a set of competing males is able to mate with the particular female they intend to.

${ }^{3}$ For example Wakelin (2001) show a positive relationship between R\&D investment and productivity in the UK manufacturing industry. Arora et al. (2008) find similar relationship between patent value and R\&D investment in the US manufacturing industry.
} 
To our knowledge, Amegashie (2001) is the first to introduce an all-pay auction in which the reward is a function of the bid and the payoff becomes non-monotonic in own bid. As a result, there exists a PSNE where one bidder places a high bid and the other bidder abstains from bidding. However, the parametric form of the payoff structure is very restrictive and the equilibria in mixed strategies are not analyzed. ${ }^{4}$ The studies by Bos and Ranger (2014), and Sacco and Schmutzler (2008) consider bid dependent prize value and are closely related to the current study. Bos and Ranger (2014) construct a two-bidder all-pay auction where the prize value is increasing in own bid in a non-decreasing returns-to-scale fashion. The authors, however, make a strong assumption that makes the winning payoff monotonically decreasing in own bid. They characterize the unique MSNE. Sacco and Schmutzler (2008) construct an $n$-bidder model. They assume that the winning prize value is an increasing concave function of own bid minus the second highest bid, and that the cost is convex. They find conditions under which a PSNE exists. To solve the equilibria in mixed strategies, they make a strong assumption of monotonically decreasing payoff in bids. Both the studies find equilibrium mixed strategies similar to that of Baye et al. (1996).

Siegel (2009) constructs a general family of games called the 'all-pay contests'. Specifically, it is an $n$-bidder model in which the bidders are asymmetric in terms of their prize valuations and cost functions. Nevertheless, even in this generic structure, the highest bidder wins a prize with certainty and the winning payoff is assumed to be monotonically decreasing in own bid. Siegel (2009) provides with a generic formula for the equilibrium payoffs and Siegel (2010) characterizes the equilibrium strategies and participation rules for this game. Siegel (2014) considers the case of our interest, with non-monotonic payoff, and characterizes the equilibrium payoffs. Nevertheless, the characterization of equilibrium is not done. Finally, the current study is similar to the study by Bertoletti (2016) who consider a known minimum bid in an all-pay auction whereas we consider a stochastic minimum bid level. Later we compare and contrast the two studies side by side.

In this study we focus on the innovation contests as all-pay auction in which there is a possibility that no bidder wins a prize with certainty; and the winning payoff is non-monotonic in

\footnotetext{
4 There are further examples of all-pay auction models in which the reward depends on the bid level. Kaplan et al. (2003) construct a model where a higher reward as well as a higher cost is incurred with a choice of lower time. They characterize equilibria under both symmetric and asymmetric valuations. Che and Gale (2006) model lobbying as an all-pay auction and take into account a cap on bidding. This structure can also be employed for bid-dependent valuation where the choice variable positively influences the cost as well as the prize value. Kaplan et al. (2002) construct an incomplete information model where the prize is separable in bidder type. Araujo et al. (2008) also use an incomplete information structure with a non-monotonic payoff and show the existence of a pure strategy Nash equilibrium.
} 
own bid. The literature shows the existence of PSNE and characterizes the equilibrium payoff, but does not characterize all the equilibria for this game. We fully characterize the PSNE and the nondegenerate MSNE. In the MSNE the support of the low-value bidder is not continuous, and both the high-value and the low-value bidders place an atom in the lower bound of their respective (and different) support. Under symmetric valuation, both bidders place an atom at zero. These results can explain the observed phenomena in innovation contests that the existing studies cannot.

\section{The Model}

\subsection{Construction of the All-pay Auction with Non-monotonic Payoff}

There are two bidders, 1 and 2, with value for a prize $V_{1}$ and $V_{2}$. Without loss of generality assume $V_{1} \geq V_{2}>0$. The bidders make costly bids, $x_{1}$ and $x_{2}$, and the lowest bidder never wins the prize. It is also possible that none of them wins the prize reflecting the situation of the 'no success' case of innovation driven by nature, or the quality standard of the buying party in a procurement auction etc. We incorporate this by introducing a random bid threshold $\widetilde{R}$ (Araujo et al., 2008; Bertoletti, 2016) with known, continuous and twice differentiable cumulative distribution function G(.), where $\mathrm{G}(0)=0, \mathrm{G}^{\prime}()=.\mathrm{g}()>$.0 , and $\mathrm{G}^{\prime \prime}()=.\mathrm{g}^{\prime}()<$.0 . The winner is determined by the highest bid that is higher than the random threshold $\widetilde{R}$. We assume complete information.

Irrespective of the outcome, bidders bear cost according to a known, continuous and twice differentiable cost function $\mathrm{C}($.$) that is increasing and weakly convex in own bid i.e., \mathrm{C}(0)=$ $0, C^{\prime}()=.c()>$.0 , and $C^{\prime \prime}()=.c^{\prime}() \geq$.0 . Hence, the payoff function of bidder $t$ (neglecting a tie) is:

$\pi_{t}\left(x_{t}, x_{-t} ; \widetilde{R}\right)=\left\{\begin{array}{rr}V_{t}-C\left(x_{t}\right) & \text { if } x_{t}>\operatorname{Max}\left(x_{-t}, \widetilde{R}\right) \\ -C\left(x_{t}\right) & \text { otherwise }\end{array}\right.$

The probability that bidder $t$ bids more than the random threshold $\widetilde{R}$ is $G\left(x_{t}\right)$. Hence, the expected payoff for bidder $t$, when he is the winner, is $\mathrm{G}\left(\mathrm{x}_{\mathrm{t}}\right) \mathrm{V}_{\mathrm{t}}-\mathrm{C}\left(\mathrm{x}_{\mathrm{t}}\right)$, if $\mathrm{x}_{\mathrm{t}}>\mathrm{x}_{-\mathrm{t}}$, where $-t$ is denoted as the bidder 'not $t$ '. G(.) here captures the diminishing returns nature of the payoff function. In case of a tie under asymmetric values $\left(V_{1}>V_{2}\right)$, if both bidders bid more than the random threshold $(\widetilde{\mathrm{R}})$, then the highest value bidder, i.e., bidder 1 wins the prize. In the case of common value $\left(V_{1}=V_{2}\right)$, such a tie is resolved by a coin toss. Given these specifications, we can rewrite the payoff function as: 
$\pi_{t}\left(x_{t}, x_{-t}\right)= \begin{cases}G\left(x_{t}\right) V_{t}-C\left(x_{t}\right) & \text { if }\left(x_{t}>x_{-t}\right) \text { or }\left(x_{t}=x_{-t}\right) \text { and }\left(V_{t}>V_{-t}\right) \\ G\left(x_{t}\right) \frac{V_{t}}{2}-C\left(x_{t}\right) & \text { if }\left(x_{t}=x_{-t}\right) \text { and }\left(V_{t}=V_{-t}\right) \\ -C\left(x_{t}\right) & \text { Otherwise }\end{cases}$

Let us call the payoff at the winning state the 'winning payoff' and denote the same for bidder $t$ as $\mathrm{W}_{\mathrm{t}}\left(\mathrm{x}_{\mathrm{t}}\right)$. The losing payoff is $\mathrm{L}_{\mathrm{t}}\left(\mathrm{x}_{\mathrm{t}}\right)$. Hence $\mathrm{W}_{\mathrm{t}}\left(\mathrm{x}_{\mathrm{t}}\right)=\mathrm{G}\left(\mathrm{x}_{\mathrm{t}}\right) \mathrm{V}_{\mathrm{t}}-\mathrm{C}\left(\mathrm{x}_{\mathrm{t}}\right)$ and $\mathrm{L}_{\mathrm{t}}\left(\mathrm{x}_{\mathrm{t}}\right)=-\mathrm{C}\left(\mathrm{x}_{\mathrm{t}}\right)$. Denote the game as $\Gamma(1,2 ; \widetilde{R})$. Also, call the graph of the winning (losing) payoff in the bid-payoff space the winning (losing) curve.

\subsection{Shape of the Winning Curves}

It is relatively easy to establish the shape of the losing curve. The winning curves for both bidders start from the origin and are strictly concave. If $C^{\prime}(0) / G^{\prime}(0)>V_{t}(t=1,2)$ then the winning payoff is negative; otherwise it is inverted U-shaped with a unique maximum: showing the nonmonotonicity. In the case of asymmetric valuation $\left(V_{1}>V_{2}\right)$, the maximum winning payoff of bidder 1 is strictly higher than that of bidder 2 . If we denote the bid that maximizes the winning payoff of bidder $t$ by $\mathrm{x}_{\mathrm{t}}^{\text {Wmax }}$, then $\mathrm{x}_{1}^{\text {Wmax }}>\mathrm{x}_{2}^{\text {Wmax }}$. As bid increases, eventually the winning payoff becomes negative. If the maximum bid that can earn bidder $t$ a non-negative winning payoff ('reach' in Siegel, 2009) is denoted by $\bar{x}_{t}$, then $\bar{x}_{1}>\bar{x}_{2}$. The proofs of these characterizations are included in the Appendix (Claims $1-7$ ). The diagrammatic representations of the curves under the different cases are shown in Figures 1.1 to 1.3, and in Figure 2.

Given this, we characterize the equilibria of the game. Sections 2.3 and 2.4 deal with the asymmetric value case $\left(V_{1}>V_{2}\right)$ whereas Section 2.5 deals with the common value case $\left(V_{1}=V_{2}\right)$.

\subsection{Pure Strategy Equilibria under Asymmetric Values $\left(V_{1}>V_{2}\right)$}

Lemma 1. If (i) $\left\{\frac{C^{\prime}(0)}{G^{\prime}(0)} \geq V_{1}\right\}$, or (ii) $\left\{\frac{C^{\prime}(0)}{G^{\prime}(0)} \in\left[V_{2}, V_{1}\right)\right\}$, or (iii) $\left\{\frac{C^{\prime}(0)}{G^{\prime}(0)}<V_{2}\right.$ and $\left.\left(x_{1}^{W m a x} \geq \bar{x}_{2}\right)\right\}$, then for the game $\Gamma(1,2 ; \widetilde{R})$ with $\left(V_{1}>V_{2}\right)$ an equilibrium in pure strategies exists. Under condition (i) the unique equilibrium strategies are $\left(x_{1}^{*}, x_{2}^{*}\right)=(0,0)$, whereas under condition (ii) or (iii) the unique equilibrium strategies are $\left(\mathrm{x}_{1}^{*}, \mathrm{x}_{2}^{*}\right)=\left(\mathrm{x}_{1}^{\text {Wmax }}, 0\right)$.

Proof: See the Appendix. 
Figure 1.1 PSNE Case (i)

$$
L_{t}, W_{t}
$$

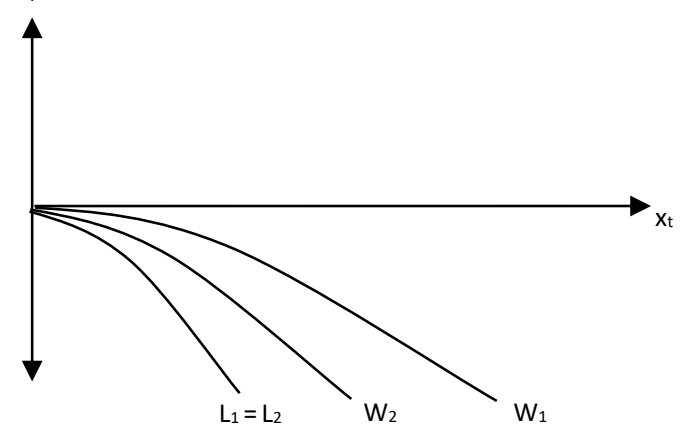

Figure 1.2 PSNE Case (ii)

$L_{t}, W_{t}$

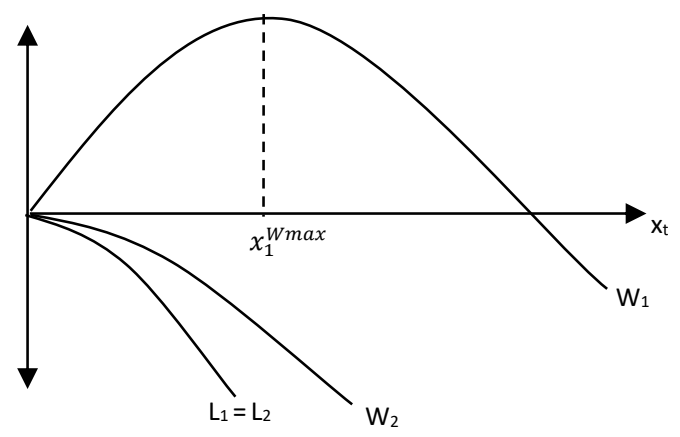

Figure 1.3 PSNE Case (iii)

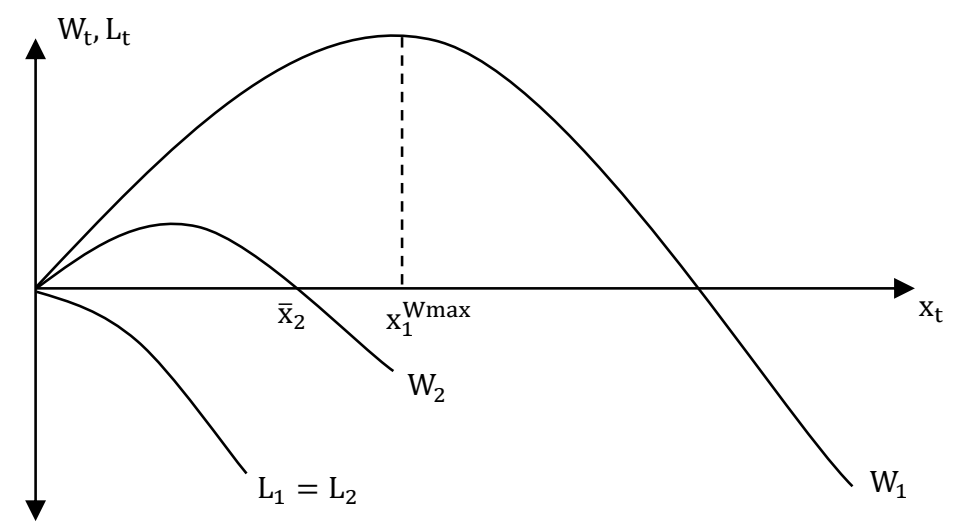

Case (i) of Lemma 1 resembles the situation of a standard all-pay auction with a very high reserve price. If the reserve price is higher than the highest valuation then the bidders bid zero. Cases (ii) and (iii) combined together correspond to the result in which one firm stays out of the innovation contest whereas the other firm spends a fixed amount. This idea is discussed in the existing literature specifically for Case (ii) (Amegashie, 2001; Bertoletti, 2016). Nonetheless, there are distinctions between the two cases that the earlier studies do not specify. First, in Case (ii) the random threshold is so high that it is always unprofitable for the weaker firm to enter the market. However, in Case (iii) it could have otherwise been profitable for the weaker firm to enter the market, but since the stronger firm makes a large enough bid, the weaker one stays out. The policy implications are also different for the two cases. In particular, a cap $\left(<\overline{\mathrm{x}}_{2}\right)$ on bidding can improve participation and competition for case (iii), but not for case (ii). These two cases, unlike the standard all-pay auction results, explain why in some situations only a single big company invests on some particular type of R\&D project and smaller companies do not. 
Lemma 2. If $\frac{\mathrm{C}^{\prime}(0)}{\mathrm{G}^{\prime}(0)}<\mathrm{V}_{2}$ and $\left(\mathrm{x}_{1}^{\mathrm{Wmax}}<\overline{\mathrm{x}}_{2}\right)$ then there exists no pure strategy Nash equilibrium for the game $\Gamma(1,2 ; \widetilde{R})$ with $\left(V_{1}>V_{2}\right)$.

Proof: See the Appendix.

Proposition 1. An equilibrium in pure strategies for the game $\Gamma(1,2 ; \widetilde{R})$ with $V_{1}>V_{2}$ exists if and only if any of the conditions (i) $\left\{\frac{\mathrm{C}^{\prime}(0)}{\mathrm{G}^{\prime}(0)} \geq \mathrm{V}_{1}\right\}$, or (ii) $\left\{\frac{\mathrm{C}^{\prime}(0)}{\mathrm{G}^{\prime}(0)} \in\left[\mathrm{V}_{2}, \mathrm{~V}_{1}\right)\right\}$, or (iii) $\left\{\frac{\mathrm{C}^{\prime}(0)}{\mathrm{G}^{\prime}(0)}<\right.$ $\mathrm{V}_{2}$ and $\left.\left(\mathrm{x}_{1}^{\text {Wmax }} \geq \overline{\mathrm{x}}_{2}\right)\right\}$ holds. Under condition (i) there exist unique equilibrium bids $\left(\mathrm{x}_{1}^{*}, \mathrm{x}_{2}^{*}\right)=$ $(0,0)$ whereas under condition (ii) or (iii) the unique equilibrium bids are $\left(\mathrm{x}_{1}^{*}, \mathrm{x}_{2}^{*}\right)=\left(\mathrm{x}_{1}^{\operatorname{Wmax}}, 0\right)$.

Proof: Lemmas 1 and 2 imply Proposition 1.

Proposition 1 reconfirms that under non-monotonic payoff pure strategy Nash equilibria exist (Amegashie, 2001; Sacco and Schmutzler, 2008; Araujo et al., 2008). Adding to these studies, we show that there are two PSNE for which the high value bidder places a positive bid and the low value bidder bids zero (cases (ii) and (iii)). Moreover, there is another PSNE, where both bidders bid zero (case (i)). For all these PSNE, the payoff characterization results of Siegel (2014) hold.

\subsection{Mixed Strategy Equilibria under Asymmetric Values $\left(V_{1}>V_{2}\right)$}

Figure 2. No Pure Strategy Equilibrium

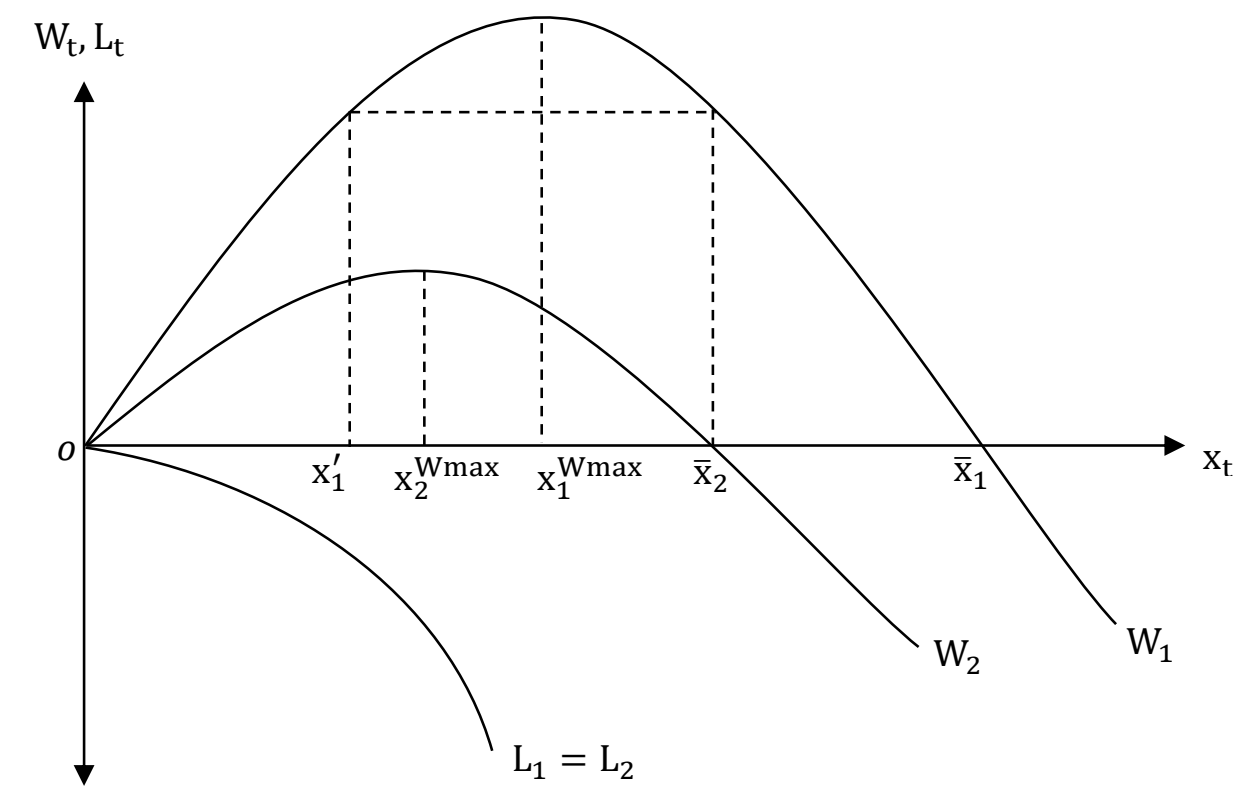


Now we consider only the case of $\left\{\frac{\mathrm{C}^{\prime}(0)}{\mathrm{G}^{\prime}(0)}<\mathrm{V}_{2}<\mathrm{V}_{1}\right.$ and $\left.\left(\mathrm{x}_{1}^{\text {Wmax }}<\overline{\mathrm{x}}_{2}\right)\right\}$, i.e., the case with no PSNE (Figure 2) and fully characterize the MSNE. This proves the existence of equilibrium in mixed strategies that follows also directly from Theorem 5 of Dasgupta and Maskin (1986). Note also that the payoff characterization results of Siegel (2014) still hold. Hence, the equilibrium payoff of bidder $1, \pi_{1}^{*}=\mathrm{W}_{1}\left(\overline{\mathrm{x}}_{2}\right)>0$ and the equilibrium payoff of bidder $2, \pi_{2}^{*}=0 .{ }^{5}$

Let us define the No-arbitrage Bid Function (NBF) of bidder $t$ to keep the other bidder indifferent as $F_{t}(x)$. In Lemmas 3 to 19 we derive the NBFs as: $F_{1}(s)=\frac{C(s)}{V_{2} G(s)}$, and $F_{2}(s)=$ $\frac{\mathrm{C}(\mathrm{s})+\mathrm{W}_{1}\left(\overline{\mathrm{x}}_{2}\right)}{\mathrm{V}_{1} \mathrm{G}(\mathrm{s})}$ and construct the shapes of the NBFs. The NBFs are drawn in Figure 3. The Lemmas (3 to 19) and the corresponding proofs are in the Appendix.

Figure 3. No-arbitrage Bid Functions

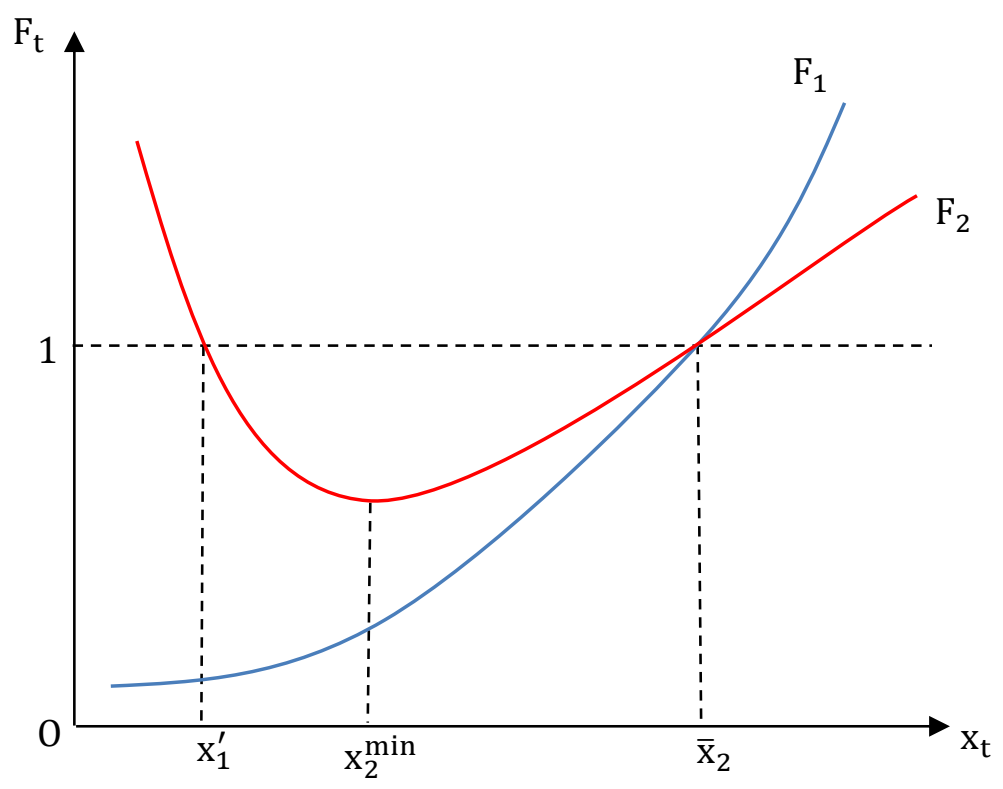

It is apparent that the NBFs are not CDFs. In particular, $\mathrm{F}_{2}(\mathrm{~s})$ is not non-decreasing. However, the capacity constrained pricing games (Osborne and Pitchick, 1986; Deneckere and Kovenock, 1996) face similar obstacles, and following the techniques employed in such games the NBFs remain the basis for the construction of equilibrium strategies. Let $\operatorname{IF}_{2}(s)=\operatorname{Inf}_{x \geq s}\left(F_{2}(x)\right)$ be the non-decreasing floor of $F_{2}(s)$. Hence, $I_{2}(s)$ equals $F_{2}(s)$ except for the interval $\left[0, x_{2}^{\min }\right)$.

\footnotetext{
${ }^{5}$ This is because the sure payoff of bidder 1 is $\mathrm{W}_{1}\left(\overline{\mathrm{x}}_{2}\right)$. Therefore, if the expected payoff of bidder 1 is not at least as high as $\mathrm{W}_{1}\left(\overline{\mathrm{x}}_{2}\right)$, then it is not an equilibrium. And it is not possible to win with certainty when bid is less than $\overline{\mathrm{x}}_{2}$. So, $\pi_{1}^{*}=\mathrm{W}_{1}\left(\overline{\mathrm{x}}_{2}\right)>0$. Similarly, bidder 2 can always earn a zero payoff by not submitting any bid, hence $\pi_{2}^{*}=0$.
} 
Note that this suggests a mass point at zero and a gap in the support between 0 and $\mathrm{x}_{2}^{\min }$ for bidder 2. However, by assumption bidder 1 wins the prize in case of a tie. Hence, bidder 2 would lose with certainty at $\underline{s}_{1}=\mathrm{x}_{2}^{\min }$ and his expected payoff at $\underline{s}_{1}=x_{2}^{\min }$ will become $-\mathrm{C}\left(\mathrm{x}_{2}^{\min }\right)<0$. Thus, $\underline{s}_{1}=x_{2}^{\min }$ cannot be in bidder 2 's support. Hence the support for bidder 2 is $\left(\mathrm{x}_{2}^{\min }, \bar{x}_{2}\right) \cup\{0\}$, and the support for bidder 1 is $\left[\mathrm{x}_{2}^{\min }, \overline{\mathrm{x}}_{2}\right]$.

$$
\text { Then } Q_{2}(s)=\left\{\begin{array}{cc}
I_{2}(s) & \text { for } s \in\left(x_{2}^{\min }, \bar{x}_{2}\right] \\
1 & \text { for }\left(s \geq \bar{x}_{2}\right)
\end{array}\right. \text { along with the mass point at zero can be a best }
$$
response function for bidder 2 - if it is a CDF. Note that $Q_{2}(s)$ is non-decreasing, non-negative, right continuous and is less than or equal to 1 for all $s$; hence, $\mathrm{Q}_{2}(\mathrm{~s})$ is a CDF and is also a strategy. Given $\mathrm{Q}_{2}$, if bidder 1 is indifferent between all bids in the interval $\left(0, \overline{\mathrm{x}}_{2}\right]$, then $F_{1}$ would be an equilibrium strategy, since it already makes bidder 2 indifferent between all bids in the interval, and he earns a strictly lower payoff by deviating from $Q_{2}$. However, since $Q_{2}$ is strictly less than $F_{2}$ over the interval $\left[0, \mathrm{x}_{2}^{\min }\right)$, bidder 1 will attach zero probability to that interval. Since bidder 1 must set the strategy that keeps bidder 2 indifferent in the points of support, it will place a mass point at $\mathrm{x}_{2}^{\min }$, the size of which equals $\mathrm{F}_{2}\left(\mathrm{x}_{2}^{\min }\right)$. Finally, bidder 1 will place zero probability to bid more than $\overline{\mathrm{x}}_{2}$.

Hence the best response of bidder 1 is: $Q_{1}(s)=\left\{\begin{array}{ll}0 & \text { for } s<x_{2}^{M i n} \\ F_{1}(s) & \text { for } x_{2}^{M i n}<s<\bar{x}_{2} \\ 1 & \text { for } s \geq \bar{x}_{2}\end{array}\right.$.

It is also easy to check that $\mathrm{Q}_{1}(\mathrm{~s})$ is non-decreasing, non-negative, right continuous, less than or equal to 1 for all s; and hence, is a strategy. In the following proposition we show that $\mathrm{Q}_{1}(\mathrm{x})$ and $\mathrm{Q}_{2}(\mathrm{x})$ constitute the unique mixed strategy Nash equilibrium of this game.

Proposition 2. The unique mixed strategy Nash equilibrium of the game $\Gamma(1,2 ; \widetilde{R})$ with restrictions $\left\{\frac{\mathrm{C}^{\prime}(0)}{\mathrm{G}^{\prime}(0)}<\mathrm{V}_{2}<\mathrm{V}_{1}\right.$ and $\left.\left(\mathrm{x}_{1}^{\mathrm{Wmax}}<\mathrm{x}_{2}\right)\right\}$ is characterized by the CDF pair $\mathrm{Q}_{1}^{*}(\mathrm{~s})$ and $\mathrm{Q}_{2}^{*}(\mathrm{~s})$. Where, the equilibrium CDF for bidder 1 is

$$
Q_{1}^{*}(s)= \begin{cases}0 & \text { for } s<x_{2}^{\min } \\ \frac{C(s)}{V_{2} G(s)} & \text { for } s \in\left[x_{2}^{\min }, \bar{x}_{2}\right] \\ 1 & \text { for } s \geq \bar{x}_{2}\end{cases}
$$

i.e., there is an atom at $x_{2}^{\min }$ with size $\alpha_{1}\left(x_{2}^{\min }\right)=\frac{C\left(x_{2}^{\min }\right)}{V_{2} G\left(x_{2}^{\min }\right)}$. The equilibrium CDF for bidder 2 is 


$$
Q_{2}^{*}(s)= \begin{cases}\frac{C\left(x_{2}^{\min }\right)+W_{1}\left(\bar{x}_{2}\right)}{V_{1} G\left(x_{2}^{\min }\right)} & \text { for } s \leq x_{2}^{\min } \\ \frac{C(s)+W_{1}\left(\bar{x}_{2}\right)}{V_{1} G(s)} & \text { for } s \in\left(x_{2}^{\min }, \bar{x}_{2}\right] \\ 1 & \text { for } s \geq \bar{x}_{2}\end{cases}
$$

i.e., there is an atom at 0 with size $\alpha_{2}(0)=\frac{\mathrm{C}\left(\mathrm{x}_{2}^{\min }\right)+\mathrm{W}_{1}\left(\overline{\mathrm{x}}_{2}\right)}{\mathrm{V}_{1} \mathrm{G}\left(\mathrm{x}_{2}^{\min }\right)}$.

Proof: We prove this proposition in two parts. First, we conclude that the pair $\left\{Q_{1}(s), Q_{2}(s)\right\}$ indeed characterizes an equilibrium. Then we show that the equilibrium is unique.

Note that $Q_{1}^{*}(s)=Q_{1}(s)$ and $Q_{2}^{*}(s)=Q_{2}(s)$. Therefore, from the previous discussion, $Q_{1}^{*}(s)$ and $\mathrm{Q}_{2}^{*}(\mathrm{~s})$ are strategies and are also best response to each other. Hence, the strategy pair $\left\{Q_{1}^{*}(s), Q_{2}^{*}(s)\right\}$ characterizes a mixed strategy Nash equilibrium for the game $\Gamma(1,2 ; \widetilde{R})$. The diagrammatic representation of the equilibrium is in Figure 4.

Figure 4. Equilibrium Distribution Functions

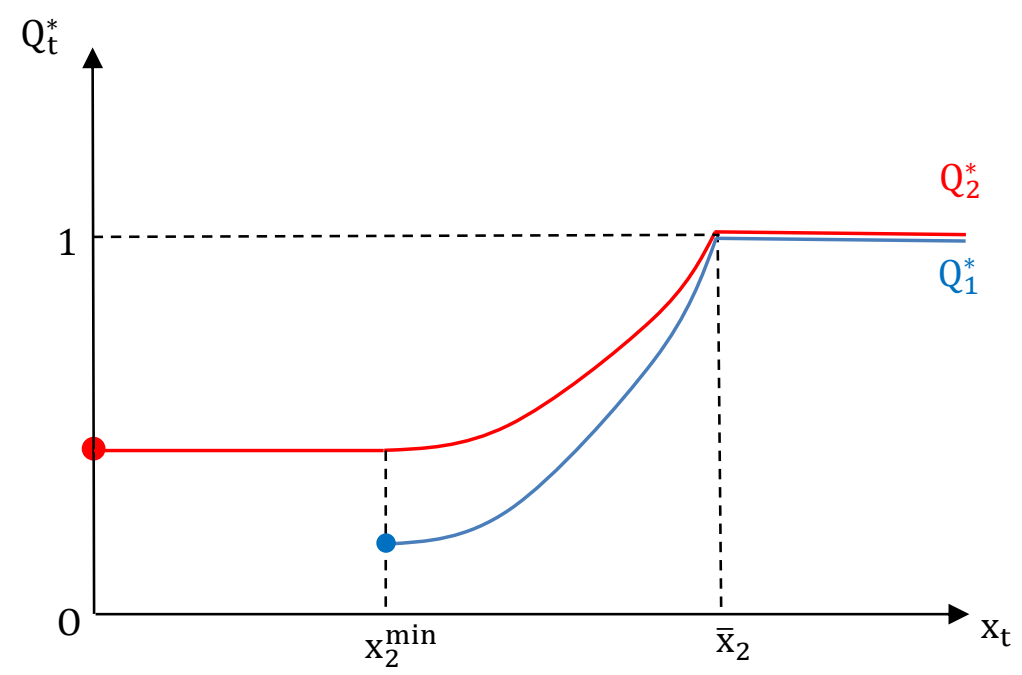

Now, if we show that the equilibrium support is unique, then the uniqueness of the equilibrium will also be proved. It is clear that the supports of equilibrium distribution coincide and are equal to the interval $\left(\mathrm{x}_{2}^{\min }, \overline{\mathrm{x}}_{2}\right]$. In addition, bidder 2 has a mass point at 0 . If $\mathrm{s} \in \operatorname{Support}\left(\mathrm{Q}_{\mathrm{t}}^{*}\right)$ then for any $\mathrm{F}_{\mathrm{t}} \neq \mathrm{Q}_{\mathrm{t}}^{*}$, the payoff of bidder $t$ when the other bidder plays equilibrium strategy, $\pi_{\mathrm{t}}\left(\mathrm{F}_{\mathrm{t}}(s), \mathrm{Q}_{-\mathrm{t}}^{*}(\mathrm{~s})\right)<\pi_{\mathrm{t}}^{*}$. Also, if $\pi_{\mathrm{t}}\left(\mathrm{F}_{\mathrm{t}}(s), \mathrm{Q}_{-\mathrm{t}}^{*}(\mathrm{~s})\right)>\pi_{\mathrm{t}}^{*}$, then $\mathrm{s} \notin \operatorname{Support}\left(\mathrm{Q}_{\mathrm{t}}^{*}\right)$. Hence the supports of the bidders' mixed strategies are unique and so are the equilibrium mixed strategies. 
Note three important features of this equilibrium, the first two of which are distinct from the standard all-pay auction equilibrium. The high-value bidder places an atom at the lower bound of his support, the low value bidder's support is discontinuous, and although the equilibrium distributions are different from the standard all-pay auction, the equilibrium payoffs of the bidders are similar to the standard case and follow the payoff characterization results of Siegel (2014).

\subsection{Characterization of Equilibria under Symmetric Value $\left(V_{1}=V_{2}\right)$}

For the case of symmetric value $\left(\mathrm{V}_{1}=\mathrm{V}_{1}=\mathrm{V}\right)$ all-pay auction with non-monotonic payoff, define $\overline{\mathrm{x}}=\left\{\mathrm{x} \neq 0: \frac{\mathrm{C}^{\prime}(0)}{\mathrm{G}^{\prime}(0)}<V \& W(\mathrm{x})=0\right\}$. It can easily be shown that for $\frac{\mathrm{C}^{\prime}(0)}{\mathrm{G}^{\prime}(0)} \geq \mathrm{V}$, the common winning curve will start from zero and is always negative. Adhering to the similar analysis as in the previous section, we derive the following proposition.

Proposition 3. A pure strategy equilibrium with unique equilibrium strategies $\left(x_{1}^{*}, x_{2}^{*}\right)=(0,0)$ exists for the game $\Gamma(1,2 ; \widetilde{\mathrm{R}})$ with $\mathrm{V}_{1}=\mathrm{V}_{2}=\mathrm{V}$ if and only if $\frac{\mathrm{C}^{\prime}(0)}{\mathrm{G}^{\prime}(0)} \geq \mathrm{V}$.

Figure 5.1 Symmetric Value Payoff Functions

Figure 5.2 Symmetric Value Equilibrium CDFs
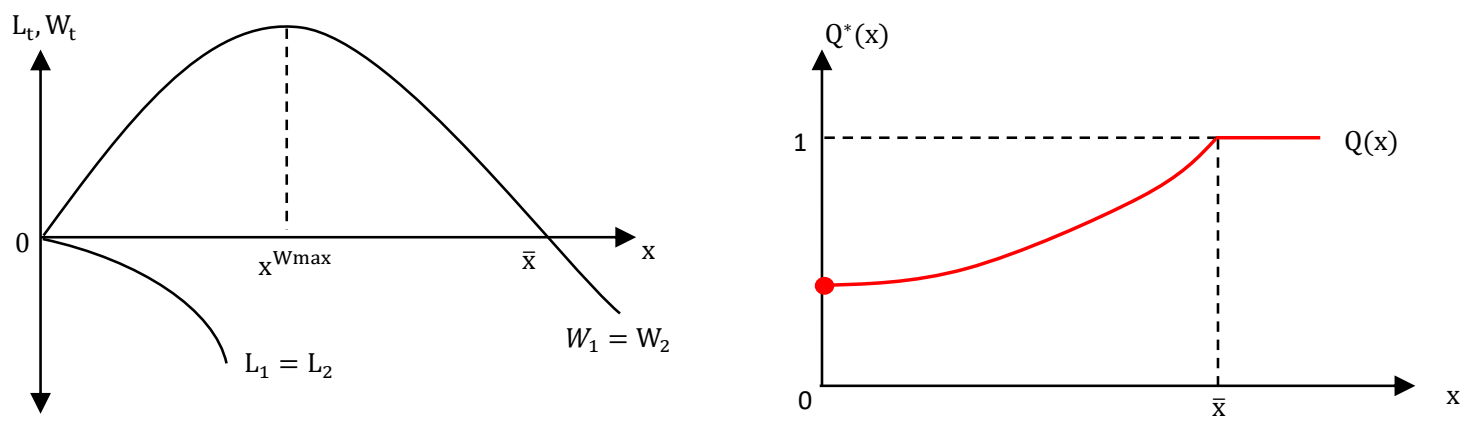

It can also be shown that for $\frac{\mathrm{C}^{\prime}(0)}{\mathrm{G}^{\prime}(0)}<V$ the common winning curve starts from zero and is inverted U-shaped. Adhering to the similar analysis as in section 2.4, we derive the following proposition. The proofs of Propositions 3 and 4 are obvious and are omitted.

Proposition 4. The unique mixed strategy Nash equilibrium of the game $\Gamma(1,2 ; \widetilde{\mathrm{R}})$ with restriction $\frac{\mathrm{C}^{\prime}(0)}{\mathrm{G}^{\prime}(0)}<\mathrm{V}_{1}=\mathrm{V}_{1}=\mathrm{V}$ is characterized by the common $\mathrm{CDF} \mathrm{Q}^{*}(\mathrm{~s})$, where 


$$
Q^{*}(s)= \begin{cases}\frac{C^{\prime}(0) / G^{\prime}(0)}{V} & \text { for } s=0 \\ \frac{C(s)}{V G(s)} & \text { for } s \in(0, \bar{x}] \\ 1 & \text { for } s \geq \bar{x}\end{cases}
$$

i.e., the common support is $[0, \overline{\mathrm{x}}]$ and in the equilibrium both the bidders place the same amount of mass $\left(\frac{\mathrm{C}^{\prime}(0)}{\mathrm{VG}^{\prime}(0)}\right)$ at 0 . Both bidders earn zero payoff in the equilibrium.

In a standard 2-bidder all-pay auction the winning payoff is positive at zero-bid and is monotonically decreasing. Hence, bidders do not place atoms at the same point in equilibrium. For example, in Baye et al. (1996), if both bidders place atoms at zero, then shifting mass to a positive bid is a profitable deviation for both the bidders. In contrast, under the current case the winning curve starts from the origin and is continuous. Hence, if a bidder shifts a mass of $\varepsilon>0$ above zero, then its marginal payoff remains zero and as a result, the bidders do not have incentive to shift mass from zero. This implies that in a contest between bidders with similar abilities sometimes some bidders opt out of the contest. In the standard common value all-pay auction, bidders do not place a mass point in equilibrium strategy, and as a result, it is not possible to explain such observation with the standard all-pay auction results.

\subsection{Overall Characterization of Equilibria}

Theorem. Propositions 1 to 4 fully characterize the equilibria for the all-pay auction with nonmonotonic payoff described by the game $\Gamma(1,2 ; \widetilde{\mathrm{R}})$.

Propositions 1 to 4 analyze mutually exclusive and exhaustive cases of the game $\Gamma(1,2 ; \widetilde{\mathrm{R}})$. The proof of the theorem is essentially the collection of the proofs of the four propositions.

\section{Discussion}

We model innovation contests as an all-pay auction in which the highest bid wins the contest only when it is above a random threshold level. This structure captures both risk against rivals and risk against nature in innovation contests. This model structure also allows us to investigate several phenomena in innovation contest that could not be investigated with standard all-pay auction model. The model structure makes the winning payoff non-monotonic in own bid, and, as a result, this study is one of the first attempts to analyze the all-pay auction with non-monotonic payoff. 
We characterize the equilibria and show that the bidders' equilibrium strategies are different from that of the standard all-pay auction with monotonic payoff. We offer several results. First, we determine the conditions for the existence of pure strategy equilibria and show a case when both bidders might abstain from bidding. Second, in the mixed strategy equilibrium, a high value bidder places a mass at the lower bound of the support. Third, we show that the equilibrium support of the low value bidder is discontinuous. Finally, bidders' place common mass points at the same point of the support in the common value case.

These results are closely related to the results of Bertoletti (2016), who consider an all-pay auction with reserve price. However, due to the stochastic nature of the 'reserve price', as well as since the payoff function is non-monotonic in the current study, there are several differences. We show a new type of pure strategy equilibrium in which the weaker bidder stays out of bidding solely due to high enough bid by the stronger bidder. Furthermore, the weight of the atoms placed in the lower bound of the respective supports of the bidders are different due to the nonmonotonicity issue. As a result, whereas the atom placed by the weaker bidder is not necessarily always higher than the atom placed by the stronger bidder.

In terms of the techniques to obtain equilibria and some aspects of the equilibria, the current results also serve as a link between the all-pay auction literature and the capacity constrained pricing (Bertrand-Edgeworth) game literature. The current model structure has some resemblance with the Bertrand-Edgeworth game with unit cost asymmetry. In some of the Bertrand-Edgeworth games firms make costly investments in capacity, and then compete on price. It is possible that the firm that charges the lower price captures and serves the whole market and the other firm loses the cost involved in capacity building. This makes such games similar to all-pay auctions. However, depending on the demand, capacities obtained and relative costs different cases arise in such games. While solving for equilibria, in both types of games the no-arbitrage functions turn out not to be CDFs and require necessary adjustments (e.g., considering the non-decreasing floor of the function in this study). Post such adjustments, in both games, one of the players places a mass point at a pure strategy that can be interpreted as "passive" behavior (in the Bertrand-Edgeworth game, the mass point is at a relatively high price; in all-pay auction, the mass point is at 0 ). This player then has a gap above (in the current all-pay auction) or below (in the Bertrand-Edgeworth game) the mass point. ${ }^{6}$

${ }^{6}$ I thank a referee for pointing out the specific connections between the games. 
Although we consider a two-player case, the analyses still provide with important and intuitive results especially since it resembles several real life situations and can explain phenomena related to the innovation process that the standard all-pay auction models cannot explain. For example, the results from the pure strategy equilibria can explain why some firms might stay out of a procurement bidding or a patent race even when there are only two competing firms. In specific, case (ii) implies that a small company does not invest in $R \& D$, even though it would find it profitable if it was the only participant. The mixed strategy equilibrium with symmetry results show that placing atoms at the same point may not be out of equilibrium behavior and explain the inactivity of some of the firms in an innovation contest even when the bidders are of the same efficiency. Moreover, in the mixed strategy equilibrium with asymmetry, the common support in the mixed strategies that starts from a positive bid explains the reason why only sufficiently high amounts of R\&D investment are observed across different industries; or why only sufficiently high quality of procurement samples in a procurement auction are submitted.

The current study is aimed at characterizing the equilibria of this model. One obvious idea for further research would be to extend the model to $n$-bidders. Another policy related extension would be to show the effects of caps on bidding. Finally, it will be intriguing to design nonmonotonic payoff all-pay auction experiments using the structure of this study.

\section{References}

Amegashie, J.A. (1999). The number of rent-seekers and aggregate rent-seeking expenditures: an unpleasant result. Public Choice, 99, 57-62.

Amegashie, J.A. (2001). An all-pay auction with a pure-strategy equilibrium. Economics Letters. 70, 79-82.

Araujo, A., de Castro, L.I., \& Moreira, H. (2008). Non-monotoniticies and the all-pay auction tiebreaking rule, Economic Theory, 35(3), 407-440.

Arora, A., Ceccagnoli, M., \& Cohen, W. M. (2008). R\&D and the patent Premium. International Journal of Industrial Organization, 26, 1153-1179.

Bastock, M. (2007). Courtship: an ethological study. Aldine Transaction, Chicago.

Baye, M. R., Kovenock, D., \& de Vries, C. G. (1993). Rigging the Lobbying Process: An Application of the All-Pay Auction. American Economic Review, 83, 289-294.

Baye M.R., Kovenock D., \& de-Vries C.G. (1996). The all-pay auction with complete information. Economic Theory, 8, 1-25

Bertoletti, P. (2016). Reserve prices in all-pay auctions with complete information. Research in Economics, 70(3), 446-453. 
Bos, O., \& Ranger, M. (2014). All-Pay Auctions with Polynomial Rewards. Annals of Economics and Statistics/Annales d'Économie et de Statistique, (115-116), 361-377.

Che, Y., \& Gale, I. (2003). Optimal Design of Research Contests. American Economic Review, 93(3), 646-71.

Che, Y., \& Gale, I. (2006). Caps on Political Lobbying: Reply. American Economic Review, 96(4), 1355-60.

Daly, M. (1978). The cost of mating. American Naturalist, 112, 771-774.

Dasgupta, P., \& Maskin, E.S. (1986). The Existence of Equilibrium in Discontinuous Economic Games, I: Theory. Review of Economic Studies, 83(1), 1-26.

Deneckere R.J., \& Kovenock, D. (1996). Bertrand-Edgeworth duopoly with unit cost asymmetry. Economic Theory, 8(1), 1-25.

Hillman, A., \& Riley, J. (1989). Politically contestable rents and transfers. Economics and Policy, $1,17-39$.

Kaplan, T. R., Luski, I., Sela, A., \& Wettstein, D. (2002). All-pay auctions with variable rewards. Journal of Industrial Economics, 4, 417-430.

Kaplan, T.R., Luski I., \& Wettstein D. (2003). Innovative activity and sunk cost. International Journal of Industrial Organization, 21, 1111 - 1133

Loury, G. C. (1979). Market Structure and Innovation. The Quarterly Journal of Economics, 93 (3), 395-410.

Osborne, M., \& Pitchik, C. (1986). Price competition in a capacity-constrained duopoly. Journal of Economic Theory, 38, 238-260

Sacco, D., \& Schmutzler, A. (2008). All-Pay Auctions with Negative Prize Externalities: Theory and Experimental Evidence. The Berkeley Electronic Press working paper

Siegel R. (2009). All-Pay Contests. Econometrica, 77(1), 71-92.

Siegel, R. (2010). Asymmetric contests with conditional investments. The American Economic Review, 100(5), 2230-2260.

Siegel, R. (2014). Contests with productive effort. International Journal of Game Theory, 43(3), 515-523.

Sozou P.D., and Seymour R.M. (2005). Costly but worthless gifts facilitate courtship. Proceedings of the Royal Society of London, Series B, 272, 1877-1884.

Tullock, G. (1980). Efficient Rent Seeking. In James M. Buchanan, Robert D. Tollison, Gordon Tullock, (Eds.), Toward a theory of the rent-seeking society. College Station, TX: Texas A\&M University Press, 97-112.

Wakelin, K. (2001). Productivity growth and R\&D expenditure in UK manufacturing firms. Research Policy, 30, 1079-1090.

Wilson, D. H. (2007). Where's My Jetpack?: A Guide to the Amazing Science Fiction Future that Never Arrived. Bloomsbury USA. 


\section{Appendix}

\section{- Characterization of the Shape of the Winning Curves}

Claim 1. The winning curves for both bidders start from the origin and are strictly concave. Proof: Given the assumptions $\mathrm{G}(0)=\mathrm{C}(0)=0$ we get $\mathrm{W}_{\mathrm{t}}(0)=0$, for $t=1$, 2; i.e., the winning curves start from the origin. Further, note that $\frac{\mathrm{d}^{2} \mathrm{~W}_{\mathrm{t}}\left(\mathrm{x}_{\mathrm{t}}\right)}{\mathrm{dx}_{\mathrm{t}}^{2}}=\mathrm{G}^{\prime \prime}\left(\mathrm{x}_{\mathrm{t}}\right) \mathrm{V}_{\mathrm{t}}-\mathrm{C}^{\prime \prime}\left(\mathrm{x}_{\mathrm{t}}\right)<0$ as $G^{\prime \prime}()<$.0 and $C^{\prime \prime}() \geq$.0 . Hence, the winning curves are strictly concave.

Claim 2. If $\frac{\mathrm{C}^{\prime}(0)}{\mathrm{G}^{\prime}(0)} \geq \mathrm{V}_{\mathrm{t}}$ then any winning payoff is non-positive.

Proof: The slope of the winning curve is $\frac{d W_{t}\left(x_{t}\right)}{d x_{t}}=G^{\prime}\left(x_{t}\right) V_{t}-C^{\prime}\left(x_{t}\right)$. Recall from Claim 1 that the winning curves start from the origin. If $\frac{C^{\prime}(0)}{G^{\prime}(0)} \geq V_{t}$ then starting from the origin the slope of the winning curve is non-positive throughout the bid range and consequently any winning payoff is also non-positive.

Claim 3. If $\frac{\mathrm{C}^{\prime}(0)}{\mathrm{G}^{\prime}(0)}<V_{\mathrm{t}}$, then starting from the origin the winning curve is inverted U-shaped with a unique maximum. As bid increases, eventually the winning curve cuts the $\mathrm{X}$-axis at a unique point and then the winning payoff becomes negative.

Proof: Starting from the origin (Claim 1), as $\frac{\mathrm{C}^{\prime}(0)}{\mathrm{G}^{\prime}(0)}<V_{\mathrm{t}}$, the winning curve has positive slope at the origin (Claim 2). But as winning curves are strictly concave (Claim 1) slope declines as bid increases; also as $\mathrm{G}^{\prime \prime}()<$.0 and $\mathrm{C}^{\prime \prime}() \geq$.0 , eventually at some unique point $\frac{\mathrm{C}^{\prime}\left(\mathrm{x}_{\mathrm{t}}\right)}{\mathrm{G}^{\prime}\left(\mathrm{x}_{\mathrm{t}}\right)}=\mathrm{V}_{\mathrm{t}}$ (follows from the uniqueness of a maximizer of a strictly concave function) and the winning curve reaches a unique maximum. After that point, $\frac{\mathrm{C}^{\prime}\left(\mathrm{x}_{\mathrm{t}}\right)}{\mathrm{G}^{\prime}\left(\mathrm{x}_{\mathrm{t}}\right)}>V_{\mathrm{t}}$ and winning curve has a strictly negative slope. As a result, as $\mathrm{x}_{\mathrm{t}}$ increases winning curve declines and cuts the $\mathrm{X}$-axis at a unique point and as $\mathrm{x}_{\mathrm{t}}$ increases further, $W_{t}$ becomes negative. 
Claim 4. Starting with no-difference, $\mathrm{W}_{1}$ and $\mathrm{W}_{2}$ diverge away from each other and the difference tends to the value difference $\left(\mathrm{V}_{1}-\mathrm{V}_{2}\right)$ as bid increases to infinity.

Proof: From the properties of $G(x),\left(W_{1}-W_{2}\right)=G(x)\left(V_{1}-V_{2}\right)$. Hence, $\left.\left(W_{1}-W_{2}\right)\right|_{0}=\left(V_{1}-\right.$ $\left.\mathrm{V}_{2}\right)\left.\mathrm{G}(\mathrm{x})\right|_{0}=0$. Also, $\frac{\mathrm{d}\left(\mathrm{W}_{1}-\mathrm{W}_{2}\right)}{\mathrm{dx}_{\mathrm{t}}}=\mathrm{G}^{\prime}\left(\mathrm{x}_{\mathrm{t}}\right)\left(\mathrm{V}_{1}-\mathrm{V}_{2}\right)>0$ and $\frac{\mathrm{d}^{2}\left(\mathrm{~W}_{1}-\mathrm{W}_{2}\right)}{\mathrm{dx}_{\mathrm{t}}{ }^{2}}=\mathrm{G}^{\prime \prime}\left(\mathrm{x}_{\mathrm{t}}\right)\left(\mathrm{V}_{1}-\mathrm{V}_{2}\right)<0$. Finally, $\lim _{x \rightarrow \infty}\left(W_{1}-W_{2}\right)=\left(V_{1}-V_{2}\right) \lim _{x \rightarrow \infty} G(x)=\left(V_{1}-V_{2}\right)$.

Claim 5. If $\frac{\mathrm{C}^{\prime}(0)}{\mathrm{G}^{\prime}(0)}<V_{2}$, define $\mathrm{x}_{\mathrm{t}}^{\mathrm{Wmax}}=\operatorname{argmax}\left(\mathrm{W}_{\mathrm{t}}\left(\mathrm{x}_{\mathrm{t}}\right)\right)$; then $\mathrm{x}_{1}^{\text {Wmax }} \geq \mathrm{x}_{2}^{\text {Wmax }}$.

Proof: From Claim 3, $\operatorname{argmax}\left(\mathrm{W}_{\mathrm{t}}\left(\mathrm{x}_{\mathrm{t}}\right)\right)$ is the solution to the first order condition $\frac{\mathrm{dW}_{\mathrm{t}}\left(\mathrm{x}_{\mathrm{t}}\right)}{\mathrm{d} \mathrm{x}_{\mathrm{t}}}=$ $G^{\prime}\left(x_{t}\right) V_{t}-C^{\prime}\left(x_{t}\right)=0$ or $\frac{C^{\prime}\left(x_{t}\right)}{G^{\prime}\left(x_{t}\right)}=V_{t}$. Define $K\left(x_{t}\right)=\frac{C^{\prime}\left(x_{t}\right)}{G^{\prime}\left(x_{t}\right)}$. Note that $\frac{d\left(\frac{C^{\prime}\left(x_{t}\right)}{G^{\prime}\left(x_{t}\right)}\right)}{d x_{t}}>0$, hence the inverse of $\mathrm{K}\left(\mathrm{x}_{\mathrm{t}}\right)$ exists and is also a monotonically increasing function. Define $\mathrm{K}^{-1}()=.\mathrm{H}($.$) ; thus,$ $\operatorname{argmax}\left(\mathrm{W}_{\mathrm{t}}\left(\mathrm{x}_{\mathrm{t}}\right)\right)=\mathrm{H}\left(\mathrm{V}_{\mathrm{t}}\right)$. By assumption $\mathrm{V}_{1} \geq \mathrm{V}_{2}$ and by construction $\mathrm{H}($.) is a monotonically increasing function, hence $\mathrm{x}_{1}^{\mathrm{Wmax}} \geq \mathrm{x}_{2}^{\mathrm{Wmax}}$.

Claim 6. $\quad \max W_{1} \geq \max W_{2}$.

Proof: From Claim 5, $\max \mathrm{W}_{\mathrm{t}}=\mathrm{G}\left(\mathrm{H}\left(\mathrm{V}_{\mathrm{t}}\right)\right) \mathrm{V}_{\mathrm{t}}-\mathrm{C}\left(\mathrm{H}\left(\mathrm{V}_{\mathrm{t}}\right)\right)$. Hence $\frac{\mathrm{dmax}_{\mathrm{t}}}{\mathrm{dV}_{\mathrm{t}}}=\mathrm{G}^{\prime}(.) \mathrm{H}^{\prime}(.) \mathrm{V}_{\mathrm{t}}+$ $\mathrm{G}()-.\mathrm{C}^{\prime}(.) \mathrm{H}^{\prime}()=.\mathrm{H}^{\prime}().\left[\mathrm{G}^{\prime}(.) \mathrm{V}_{\mathrm{t}}-\mathrm{C}^{\prime}().\right]+\mathrm{G}()=.\mathrm{G}()>$.0 as $\left[\mathrm{G}^{\prime}(.) \mathrm{V}_{\mathrm{t}}-\mathrm{C}^{\prime}().\right]=0$ for maximization and $\mathrm{V}_{\mathrm{t}}>0$ for $t=1,2$. Given $\mathrm{V}_{1} \geq \mathrm{V}_{2}$, we confirm $\max \mathrm{W}_{1} \geq \max \mathrm{W}_{2}$.

Claim 7. Define $\bar{x}_{t}=\left\{x_{t} \neq 0: \frac{C^{\prime}(0)}{G^{\prime}(0)}<V_{t} \& W_{t}\left(x_{t}\right)=0\right\}$ i.e., $\bar{x}_{t}$ is the unique positive bid by bidder $\mathrm{t}$ (Claim 3) for which his/her winning payoff is zero. ${ }^{7}$ Then $\overline{\mathrm{x}}_{1}>\overline{\mathrm{x}}_{2}$.

Proof: From Claim 4, $\left(\mathrm{W}_{1}(\mathrm{x})-\mathrm{W}_{2}(\mathrm{x})\right)>0 \forall x>0$ and by definition $\mathrm{W}_{\mathrm{t}}\left(\overline{\mathrm{x}}_{\mathrm{t}}\right)=0$. Consequently, $\mathrm{W}_{1}\left(\overline{\mathrm{x}}_{2}\right)>\mathrm{W}_{2}\left(\overline{\mathrm{x}}_{2}\right)=0=\mathrm{W}_{1}\left(\overline{\mathrm{x}}_{1}\right)$. Hence, the inverted U-shape of winning curve $\mathrm{W}_{1}($.$) (Claim 3) confirms \overline{\mathrm{x}}_{1}>\overline{\mathrm{x}}_{2}$.

These claims together constitutes the shape of the winning curves.

\footnotetext{
${ }^{7} \overline{\mathrm{X}}_{\mathrm{t}}$ is defined as the 'reach of bidder $t$ ' in Siegel (2009a, b)
} 


\section{- Proofs of Lemmas 1 to 19.}

Lemma 1. An equilibrium in pure strategies for the game $\Gamma(1,2 ; \widetilde{R})$ exists under condition (i) $\left\{\frac{\mathrm{C}^{\prime}(0)}{\mathrm{G}^{\prime}(0)} \geq \mathrm{V}_{1}\right\}$ or (ii) $\left\{\frac{\mathrm{C}^{\prime}(0)}{\mathrm{G}^{\prime}(0)} \in\left[\mathrm{V}_{2}, \mathrm{~V}_{1}\right)\right\}$ or (iii) $\left\{\frac{\mathrm{C}^{\prime}(0)}{\mathrm{G}^{\prime}(0)}<\mathrm{V}_{2}\right.$ and $\left.\left(\mathrm{x}_{1}^{\mathrm{Wmax}} \geq \overline{\mathrm{x}}_{2}\right)\right\}$. Moreover, under condition (i) the unique equilibrium bids are $\left(\mathrm{x}_{1}^{*}, \mathrm{x}_{2}^{*}\right)=(0,0)$, whereas under condition (ii) or (iii) the unique equilibrium bids are $\left(\mathrm{x}_{1}^{*}, \mathrm{x}_{2}^{*}\right)=\left(\mathrm{x}_{1}^{\mathrm{Wmax}}, 0\right)$.

Proof: (i) If $\frac{\mathrm{C}^{\prime}(0)}{\mathrm{G}^{\prime}(0)} \geq \mathrm{V}_{1}$ then by Claim 2 the winning payoffs are always non-positive and bidding any positive amount with positive probability ensures loss. So, in equilibrium both the bidders bid zero, i.e., $\mathrm{x}_{1}^{*}=\mathrm{x}_{2}^{*}=0$. (ii) If $\frac{\mathrm{C}^{\prime}(0)}{\mathrm{G}^{\prime}(0)} \in\left[\mathrm{V}_{2}, \mathrm{~V}_{1}\right)$ then bidder 2's winning payoff is always nonpositive and following the same logic as in (i), $x_{2}^{*}=0$. Bidder 1 's winning curve is inverted Ushaped and given bidder 2 bids 0 with certainty, bidder 1 maximizes its payoff by always bidding $\mathrm{x}_{1}^{*}=\operatorname{argmax}\left(\mathrm{W}_{1}\left(\mathrm{x}_{1}\right)\right)=\mathrm{x}_{1}^{\mathrm{Wmax}}>0$. (iii) If $\frac{\mathrm{C}^{\prime}(0)}{\mathrm{G}^{\prime}(0)}<\mathrm{V}_{2}$, then in some sufficiently small neighborhood of zero bid, the winning payoff is positive for both bidders. When $\left(\mathrm{x}_{1}^{\mathrm{Wmax}} \geq \overline{\mathrm{x}}_{2}\right)$ then knowing bidder 2 never bids at or over $\bar{x}_{2}$ (as that will result in a negative payoff whereas a zero-bid ensures a zero payoff), any bid between $\overline{\mathrm{x}}_{2}$ and $\overline{\mathrm{x}}_{1}$ gives a sure positive payoff to bidder 1. The sure payoff reflected by the winning curve is maximized at $\mathrm{x}_{1}^{\mathrm{Wmax}}$. Hence, bidder 1 bids at $\mathrm{x}_{1}^{*}=\mathrm{x}_{1}^{\text {Wmax }}>\overline{\mathrm{x}}_{2}$ with certainty. Knowing this, bidder 2 bids $\mathrm{x}_{2}^{*}=0$ with certainty.

Lemma 2. If $\frac{\mathrm{C}^{\prime}(0)}{\mathrm{G}^{\prime}(0)}<\mathrm{V}_{2}$ and $\left(\mathrm{x}_{1}^{\mathrm{Wmax}}<\overline{\mathrm{x}}_{2}\right)$ then there exists no pure strategy Nash equilibrium for the game $\Gamma(1,2 ; \widetilde{R})$.

Proof: We prove the non-existence of PSNE by the way of contradiction. Suppose there exists a $\operatorname{PSNE}\left\{\hat{\mathrm{x}}_{1}, \hat{\mathrm{x}}_{2}\right\}$. Note first that $\hat{\mathrm{x}}_{1}=\hat{\mathrm{x}}_{2}=0$ is not an equilibrium as any of the bidder $t$ can bid $\mathrm{x}_{\mathrm{t}}^{\text {Wmax }}$. Similarly, bidder $t$ bidding $\mathrm{x}_{\mathrm{t}}^{\text {Wmax }}$ and the other bidding 0 cannot be an equilibrium either, as the other bidder can make a positive payoff by bidding $x_{-t}=\mathrm{x}_{\mathrm{t}}^{\text {Wmax }}+\varepsilon$. It is not possible in the equilibrium that $\hat{\mathrm{x}}_{1}<\hat{\mathrm{x}}_{2}$, as $\overline{\mathrm{x}}_{1} \geq \overline{\mathrm{x}}_{2}$. It is also not possible $\hat{\mathrm{x}}_{1}, \hat{\mathrm{x}}_{2}>\overline{\mathrm{x}}_{2}$ as bidder 2 will never bid more than $\bar{x}_{2}$, and knowing that bidder 1 will never bid more than $\bar{x}_{2}$ either. Hence, the possible PSNE can be only in the range $\bar{x}_{2} \geq \hat{x}_{1} \geq \hat{x}_{2}>0$. Suppose, now that bidder 1 bids $\bar{x}_{2}$, then the best response of bidder 2 is to bid 0 . But if bidder 2 bids 0 , then the best response of bidder 1 is to bid $\mathrm{x}_{1}^{\text {Wmax }}$. We know, however, that is not an equilibrium and bidder 2 will bid $\mathrm{x}_{1}^{\text {Wmax }}+\varepsilon$. Bidder 
1 in such a case will out bid bidder 2 and will keep on increasing the bid until $\mathrm{x}_{1}=\overline{\mathrm{x}}_{2}$. But then the whole cycle starts again and no $\left\{\hat{\mathrm{x}}_{1}, \hat{\mathrm{x}}_{2}\right\}$ can constitute a PSNE.

In the following we first define and derive the no-arbitrage bid functions, and then derive the equilibrium strategies from the no-arbitrage bid functions.

Lemma 3. Denote $\bar{s}_{t}=\inf \left\{x: F_{t}(x)=1\right\}$ and $\underline{s}_{t}=\sup \left\{x: F_{t}(x)=0\right\}$, then $0 \leq \underline{s}_{t} \leq \bar{s}_{t} \leq \bar{x}_{t}$.

Proof: $0 \leq \underline{s}_{t}$, as by assumption bids cannot be negative. $\underline{s}_{t} \leq \bar{s}_{t}$ comes from the definitions of $\underline{s}_{t}$ and $\bar{s}_{t}$ and strict inequality holds if there is no pure strategy for any of the bidders. By definition $\overline{\mathrm{s}}_{\mathrm{t}}=\inf \left\{\mathrm{x}: \mathrm{F}_{\mathrm{t}}(\mathrm{x})=1\right\}$. If bidder $t$ places a mass on any bid more than $\overline{\mathrm{x}}_{\mathrm{t}}$ then it will make a sure negative payoff for that mass and as a result the expected payoff will fall. He can always increase the expected payoff by placing that mass at $0 . \therefore \overline{\mathrm{s}}_{\mathrm{t}} \leq \overline{\mathrm{x}}_{\mathrm{t}}$.

Lemma 4. $\bar{s}_{\mathrm{t}} \leq \overline{\mathrm{x}}_{2}$.

Proof: From Lemma $3, \overline{\mathrm{s}}_{2} \leq \overline{\mathrm{x}}_{2}$. At $\overline{\mathrm{x}}_{2}$ bidder 1 earns a sure payoff of $\mathrm{W}_{1}\left(\overline{\mathrm{x}}_{2}\right) .{ }^{8}$ Therefore at $\overline{\mathrm{x}}_{2}$, The No-PSNE case implies $\mathrm{x}_{1}^{\text {Wmax }}<\overline{\mathrm{x}}_{2}$, hence $\mathrm{W}_{1}($.$) is falling at \overline{\mathrm{x}}_{2}$ and placing any bid above $\overline{\mathrm{x}}_{2}$ with positive probability strictly reduces expected payoff for bidder 1 . So, bidder 1 never places a bid above $\overline{\mathrm{x}}_{2}$, i. e. , $\overline{\mathrm{s}}_{1} \leq \overline{\mathrm{x}}_{2}$ as well.

Lemma 5. Define $\mathrm{x}_{1}^{\prime}=\left\{\mathrm{x} \neq \overline{\mathrm{x}}_{2}: \mathrm{W}_{1}(\mathrm{x})=\mathrm{W}_{1}\left(\overline{\mathrm{x}}_{2}\right)\right\}$, then $\mathrm{x}_{1}^{\prime}<\mathrm{x}_{1}^{\mathrm{Wmax}}\left(<\overline{\mathrm{x}}_{2}\right)$.

Proof: From Claim 3, $\mathrm{W}_{1}(\mathrm{x})$ curve is inverted $\mathrm{U}$ shaped and from the definition of $\mathrm{x}_{1}^{\prime}, \mathrm{W}_{1}\left(\mathrm{x}_{1}^{\prime}\right)=$ $\mathrm{W}_{1}\left(\overline{\mathrm{x}}_{2}\right)$. Given the stated condition of no PSNE $\mathrm{x}_{1}^{\text {Wmax }}<\overline{\mathrm{x}}_{2}$, we must have $\mathrm{x}_{1}^{\prime}<\mathrm{x}_{1}^{\text {Wmax }}$. Note that the strict concavity property of $\mathrm{G}\left(\right.$.) function ensures a unique $\mathrm{x}_{1}^{\prime}$.

Lemma 6. $\underline{s}_{1}>x_{1}^{\prime}$.

Proof: Lemma $5\left(\mathrm{x}_{1}^{\prime}<\mathrm{x}_{1}^{\text {Wmax }}\right)$ implies that at $\mathrm{x}_{1}^{\prime}, \mathrm{W}_{1}($.$) is increasing. Hence, if bidder 1$ bids $\mathrm{x}_{1} \leq \mathrm{x}_{1}^{\prime}$ with positive probability, then $\mathrm{W}_{1}\left(\mathrm{x}_{1}\right) \leq \mathrm{W}_{1}\left(\mathrm{x}_{1}^{\prime}\right)=\mathrm{W}_{1}\left(\overline{\mathrm{x}}_{2}\right)$, and there is a chance that bidder 1 will lose. But Bidder 1 can always bid $\bar{x}_{2}$ to earn a sure payoff of $\mathrm{W}_{1}\left(\overline{\mathrm{x}}_{2}\right)$. i.e., bidding any amount $\leq \mathrm{x}_{1}^{\prime}$ provides less payoff to bidder 1 than the sure payoff. Thus, bidder 1 never places a positive probability to bids up to $x_{1}^{\prime}$, implying $\underline{s}_{1}>x_{1}^{\prime}$.

\footnotetext{
${ }^{8} \mathrm{~W}_{1}\left(\overline{\mathrm{x}}_{2}\right)$ is the 'power' of bidder 1 as in Siegel (2009).
} 
Lemma 7. In equilibrium, the support of bidder 2's distribution is contained in 0 and $\left(\mathrm{x}_{1}^{\prime}, \overline{\mathrm{x}}_{2}\right]$. Proof: From Lemma $6, \underline{s}_{1}>x_{1}^{\prime}$. Knowing this, bidder 2 also never places a positive probability in $\left(0, x_{1}^{\prime}\right]$ as that ensures a negative payoff. So, bidder 2 places positive probability of bidding in either 0 or between $\left(\mathrm{x}_{1}^{\prime}, \overline{\mathrm{x}}_{2}\right]$, i.e., bidder 2 's support is contained in 0 and $\left(\mathrm{x}_{1}^{\prime}, \overline{\mathrm{x}}_{2}\right]$.

Lemma 8. $\underline{s}_{2}=0$.

Proof: From Siegel (2014), $\pi_{1}^{*}>0$ and $\pi_{2}^{*}=0$. Combining with the fact that bidder 1 must win with positive probability over the whole support to attain $\pi_{1}^{*}>0$ we must have $\underline{s}_{2}=0$.

Lemma 9. $\overline{\mathrm{s}}_{1}=\overline{\mathrm{x}}_{2}$.

Proof: This comes directly from Siegel (2014).

Lemma 10. $\overline{\mathrm{s}}_{2}=\overline{\mathrm{x}}_{2}$.

Proof: From Lemma 4, $\overline{\mathrm{s}}_{2} \leq \overline{\mathrm{x}}_{2}$ and from Lemma 9, $\overline{\mathrm{s}}_{1}=\overline{\mathrm{x}}_{2}$. Suppose $\overline{\mathrm{s}}_{2}<\overline{\mathrm{x}}_{2}$ then because $\mathrm{W}_{1}($.$) is decreasing at \overline{\mathrm{x}}_{2}$, placing any bid $\mathrm{x}_{1} \in\left[\overline{\mathrm{s}}_{2}, \overline{\mathrm{x}}_{2}\right)$ ensures bidder 1 a sure payoff of $\mathrm{W}_{1}\left(\mathrm{x}_{1}\right)>\mathrm{W}_{1}\left(\overline{\mathrm{x}}_{2}\right)$ : a contradiction with Siegel (2014). Hence $\overline{\mathrm{s}}_{2}=\overline{\mathrm{x}}_{2}$.

Lemma 11. $F_{2}\left(\underline{s}_{1}\right)=F_{2}(0)$.

Proof: Suppose not. Then bidder 2 places a positive probability of bidding in the semi-open interval $\left(0, \underline{s}_{1}\right]$. But that ensures a negative payoff which is contradictory to Siegel (2014).

Lemma 12. Bidder 1's support is connected on the interval $\left(\underline{s}_{1}, \overline{\mathrm{x}}_{2}\right)$.

Proof: Suppose not and there is a gap $(a, b) \subseteq\left(\underline{s}_{1}, \bar{x}_{2}\right)$, where $b>a$; the gap can be a singleton. In equilibrium bidder 1 earns the same expected payoff in every point of $\left(\underline{s}_{1}, a\right) \cup\left(b, \overline{\mathrm{x}}_{2}\right)$. But with this gap bidder 1 can shift mass from $\mathrm{N}_{\varepsilon+}(b)$ to point $a$. In such a case his probability of winning remains the same but cost goes down; and as a result payoff at $\mathrm{N}_{\varepsilon+}(b)$ goes up - which is a contradiction. Hence, the support cannot have gap.

Lemma 13. Support of $F_{2}$ is contained in Support of $F_{1} \cup\{0\}$.

Proof: Suppose not. Then the support of $\mathrm{F}_{2}$ includes at least parts of interval $\left(\mathrm{x}_{1}^{\prime}, \underline{\mathrm{s}}_{1}\right)$. However, that is contradictory to Lemma 11. 
Lemma 14. If $\alpha_{t}(s)$ is the amount of mass bidder $t$ places at point $s$, then $\alpha_{2}(0) \in(0,1)$.

Proof: From Lemma 11, $\operatorname{Prob}\left(\mathrm{x}_{2}<\underline{\mathrm{s}}_{1}\right)=\alpha_{2}(0) . \therefore \pi_{1}\left(\underline{s}_{1}\right)=\alpha_{2}(0) \mathrm{G}\left(\underline{\mathrm{s}}_{1}\right) \mathrm{V}_{1}-\mathrm{C}\left(\underline{\mathrm{s}}_{1}\right)$. Hence, if $\alpha_{2}(0)=0$ then $\pi_{1}\left(\underline{s}_{1}\right)=-C\left(\underline{s}_{1}\right)<W_{1}\left(\bar{x}_{2}\right)$ and if $\alpha_{2}(0)=1$ then bidding any $\mathrm{x}_{1} \in\left(\mathrm{x}_{1}^{\prime}, \overline{\mathrm{x}}_{2}\right)$ ensures bidder 1 a payoff $W_{1}\left(x_{1}\right)>W_{1}\left(x_{1}^{\prime}\right)=W_{1}\left(\bar{x}_{2}\right)$ both of which are contradictory with Lemma 8. $\therefore \alpha_{2}(0) \in(0,1)$.

Lemma 15. $\alpha_{1}\left(\underline{s}_{1}\right) \in(0,1)$.

Proof: From Lemma $6, \underline{s}_{1}>0$ and from Lemma $14, \alpha_{2}(0)>0$. If $\alpha_{1}\left(\underline{s}_{1}\right)=0$, then given Lemmas 12 and 13, at $\underline{s}_{1}$ bidder 2 loses with certainty and payoff of bidder 2 becomes $-\mathrm{C}\left(\underline{s}_{1}\right)<$ 0 ; and if $\alpha_{1}\left(\underline{s}_{1}\right)=1$ then for any small $\varepsilon>0$, bidding $\left(\underline{s}_{1}+\varepsilon\right)$ gives bidder 2 a sure payoff of $\mathrm{W}_{2}\left(\underline{\mathrm{s}}_{1}+\varepsilon\right)>0$ : both of which are contradictory with Siegel $(2014) . \therefore \alpha_{1}\left(\underline{s}_{1}\right) \in(0,1)$.

Lemma 16. A No-arbitrage Bid Function (NBF) of bidder 1 to keep bidder 2 indifferent is: $\mathrm{F}_{1}(\mathrm{~s})=\frac{\mathrm{C}(\mathrm{s})}{\mathrm{V}_{2} \mathrm{G}(\mathrm{s})}$, and an NBF of bidder 2 to keep bidder 1 indifferent is: $\mathrm{F}_{2}(\mathrm{~s})=\frac{\mathrm{C}(\mathrm{s})+\mathrm{W}_{1}\left(\overline{\mathrm{x}}_{2}\right)}{\mathrm{V}_{1} \mathrm{G}(\mathrm{s})}$.

Proof: To keep bidder 1 indifferent, bidder 2 places the bid function $F_{2}($.$) in a way such that$ $\mathrm{F}_{2}(\mathrm{~s}) \mathrm{V}_{1} \mathrm{G}(\mathrm{s})-\mathrm{C}(\mathrm{s})=\pi_{1}^{*}=\mathrm{W}_{1}\left(\overline{\mathrm{x}}_{2}\right)$. Solving for $\mathrm{F}_{2}(\mathrm{~s})$ yields the NBF of bidder $2: \mathrm{F}_{2}(\mathrm{~s})=$ $\frac{\mathrm{C}(\mathrm{s})+\mathrm{W}_{1}\left(\overline{\mathrm{x}}_{2}\right)}{\mathrm{V}_{1} \mathrm{G}(\mathrm{s})}$. Similarly, bidder 1 places the bid function $\mathrm{F}_{1}($.$) in a way such that \mathrm{F}_{1}(\mathrm{~s}) \mathrm{V}_{2} \mathrm{G}(\mathrm{s})-$ $C(s)=\pi_{2}^{*}=0$. Solving for $F_{1}($.$) yields N B F$ of bidder $2: F_{1}(s)=\frac{C(s)}{V_{2} G(s)}$.

Lemma 17. $\lim _{\mathrm{s} \rightarrow 0} \mathrm{~F}_{1}(\mathrm{~s})<1, \mathrm{~F}_{1}\left(\mathrm{x}_{1}^{\prime}\right)<1$, and $\mathrm{F}_{1}\left(\overline{\mathrm{x}}_{2}\right)=1$.

Proof: Using L'Hospital rule: $\lim _{\mathrm{s} \rightarrow 0} \mathrm{~F}_{1}(\mathrm{~s})=\frac{\lim _{\mathrm{s} \rightarrow 0} \frac{\mathrm{dC}(\mathrm{s})}{\mathrm{ds}}}{\lim _{\mathrm{s} \rightarrow 0} \frac{\mathrm{d}\left(\mathrm{V}_{2} \mathrm{G}(\mathrm{s})\right)}{\mathrm{ds}}}=\frac{\mathrm{C}^{\prime}(0)}{\mathrm{V}_{2} \mathrm{G}^{\prime}(0)}<1$ as $\frac{\mathrm{C}^{\prime}(0)}{\mathrm{G}^{\prime}(0)}<\mathrm{V}_{2}$.

Also, $\mathrm{F}_{1}\left(\mathrm{x}_{1}^{\prime}\right)=\frac{\mathrm{C}\left(\mathrm{x}_{1}^{\prime}\right)}{\mathrm{V}_{2} \mathrm{G}\left(\mathrm{x}_{1}^{\prime}\right)}=\frac{\mathrm{C}\left(\mathrm{x}_{1}^{\prime}\right)}{\left\{\mathrm{V}_{2} \mathrm{G}\left(\mathrm{x}_{1}^{\prime}\right)-\mathrm{C}\left(\mathrm{x}_{1}^{\prime}\right)\right\}+\mathrm{C}\left(\mathrm{x}_{1}^{\prime}\right)}=\frac{\mathrm{x}_{1}^{\prime}}{\mathrm{W}_{1}\left(\mathrm{x}_{1}^{\prime}\right)+\mathrm{C}\left(\mathrm{x}_{1}^{\prime}\right)}<1$ as $\mathrm{W}_{1}\left(\mathrm{x}_{1}^{\prime}\right)=\mathrm{W}_{1}\left(\overline{\mathrm{x}}_{2}\right)>0$.

Recall also that $\overline{\mathrm{x}}_{2}$ is the 'reach' of bidder 2. By the definition of bidder 2's reach $\frac{\mathrm{C}\left(\overline{\mathrm{x}}_{2}\right)}{\mathrm{V}_{2} \mathrm{G}\left(\overline{\mathrm{x}}_{2}\right)}=1$. Hence, $\mathrm{F}_{1}\left(\overline{\mathrm{x}}_{2}\right)=1$.

Lemma 18. $\mathrm{F}_{1}(\mathrm{~s})$ is monotonically increasing in the closed interval $\left[\mathrm{x}_{1}^{\prime}, \overline{\mathrm{x}}_{2}\right]$.

Proof: From Lemma $17, \mathrm{~F}_{1}\left(\overline{\mathrm{x}}_{2}\right)>\mathrm{F}_{1}\left(\mathrm{x}_{1}^{\prime}\right)$. If there exists no extreme point of $\mathrm{F}_{1}($.$) within the$ open interval $\left(\mathrm{x}_{1}^{\prime}, \overline{\mathrm{x}}_{2}\right)$ then it means that $\mathrm{F}_{1}(\mathrm{~s})$ is monotonically increasing in $\left(\mathrm{x}_{1}^{\prime}, \overline{\mathrm{x}}_{2}\right)$. In any 
extreme point of $F_{1}(s), \frac{d F_{1}(s)}{d s}=\frac{V_{2} G(s) C^{\prime}(s)-C(s) V_{2} G^{\prime}(s)}{\left[V_{2} G(s)\right]^{2}}=0$, i.e., $\left[G(s) C^{\prime}(s)-C(s) G^{\prime}(s)\right]=0$. But, $\left[G(s) C^{\prime}(s)-C(s) G^{\prime}(s)\right]$ is a strictly upward rising curve from origin since $\left[G(s) C^{\prime}(s)-\right.$ $\left.\mathrm{C}(\mathrm{s}) \mathrm{G}^{\prime}(\mathrm{s})\right]\left.\right|_{0}=0$, and $\frac{\mathrm{d}\left[\mathrm{G}(\mathrm{s}) \mathrm{C}^{\prime}(\mathrm{s})-\mathrm{C}(\mathrm{s}) \mathrm{G}^{\prime}(\mathrm{s})\right]}{\mathrm{ds}}=\mathrm{G}(\mathrm{s}) \mathrm{C}^{\prime \prime}(\mathrm{s})-\mathrm{C}(\mathrm{s}) \mathrm{G}^{\prime \prime}(\mathrm{s})>0 \forall \mathrm{s}>0$. Hence, there is no solution except origin for $\left[\mathrm{G}(\mathrm{s}) \mathrm{C}^{\prime}(\mathrm{s})-\mathrm{C}(\mathrm{s}) \mathrm{G}^{\prime}(\mathrm{s})\right]=0$, and there exists no extreme point for $\mathrm{F}_{1}(\mathrm{~s})$ within the interval $\left(\mathrm{x}_{1}^{\prime}, \overline{\mathrm{x}}_{2}\right)$. Thus, $\mathrm{F}_{1}(\mathrm{~s})$ is monotonically increasing in $\left[\mathrm{x}_{1}^{\prime}, \overline{\mathrm{x}}_{2}\right]$.

Lemma 19. $\mathrm{F}_{2}(\mathrm{~s})$ starts from infinity, monotonically decreases to 1 at $\mathrm{s}=\mathrm{x}_{1}^{\prime}$, reaches unique minimum within the open interval $\left(\mathrm{x}_{1}^{\prime}, \overline{\mathrm{x}}_{2}\right)$ and then monotonically increases to 1 at $\mathrm{s}=\overline{\mathrm{x}}_{2}$.

Proof: From Lemma 16, $\mathrm{F}_{2}(\mathrm{~s})=\frac{\mathrm{C}(\mathrm{s})+\mathrm{W}_{1}\left(\overline{\mathrm{x}}_{2}\right)}{\mathrm{V}_{1} \mathrm{G}(\mathrm{s})}, \therefore \mathrm{F}_{2}(0)=\infty$. And $\mathrm{F}_{2}\left(\mathrm{x}_{1}^{\prime}\right)=\frac{\mathrm{C}\left(\mathrm{x}_{1}^{\prime}\right)+\mathrm{W}_{1}\left(\overline{\mathrm{x}}_{2}\right)}{\mathrm{V}_{1} \mathrm{G}\left(\mathrm{x}_{1}^{\prime}\right)}=$ $\frac{\mathrm{C}\left(\mathrm{x}_{1}^{\prime}\right)+\mathrm{W}_{1}\left(\mathrm{x}_{1}^{\prime}\right)}{\mathrm{V}_{1} \mathrm{G}\left(\mathrm{x}_{1}^{\prime}\right)}=\frac{\mathrm{C}\left(\mathrm{x}_{1}^{\prime}\right)+\left\{\mathrm{V}_{1} \mathrm{G}\left(\mathrm{x}_{1}^{\prime}\right)-\mathrm{C}\left(\mathrm{x}_{1}^{\prime}\right)\right\}}{\mathrm{V}_{1} \mathrm{G}\left(\mathrm{x}_{1}^{\prime}\right)}=1$. Also, $\mathrm{F}_{2}\left(\overline{\mathrm{x}}_{2}\right)=\frac{\mathrm{C}\left(\overline{\mathrm{x}}_{2}\right)+\mathrm{W}_{1}\left(\overline{\mathrm{x}}_{2}\right)}{\mathrm{V}_{1} \mathrm{G}\left(\overline{\mathrm{x}}_{2}\right)}=\frac{\mathrm{C}\left(\overline{\mathrm{x}}_{2}\right)+\left\{\mathrm{V}_{1} \mathrm{G}\left(\overline{\mathrm{x}}_{2}\right)-\mathrm{C}\left(\overline{\mathrm{x}}_{2}\right)\right\}}{\mathrm{V}_{1} \mathrm{G}\left(\overline{\mathrm{x}}_{2}\right)}=1$. If we prove that $F_{2}($.$) is decreasing at x_{1}^{\prime}$ then there will be at least one minimum point of $F_{2}($.$) in$ the open interval $\left(x_{1}^{\prime}, \bar{x}_{2}\right)$. Note that $\frac{\mathrm{dF}_{2}(\mathrm{~s})}{\mathrm{ds}}=\frac{\mathrm{V}_{1} \mathrm{G}(\mathrm{s}) \mathrm{C}^{\prime}(\mathrm{s})-\left\{\mathrm{C}(\mathrm{s})+\mathrm{W}_{1}\left(\overline{\mathrm{x}}_{2}\right)\right\} \mathrm{V}_{1} \mathrm{G}^{\prime}(\mathrm{s})}{\left[\mathrm{V}_{1} \mathrm{G}(\mathrm{s})\right]^{2}}$. Hence $\operatorname{Sign}\left(\frac{\mathrm{dF}_{2}(\mathrm{~s})}{\mathrm{ds}}\right)=\operatorname{Sign}\left(\mathrm{G}(\mathrm{s}) \mathrm{C}^{\prime}(\mathrm{s})-\left\{\mathrm{C}(\mathrm{s})+\mathrm{W}_{1}\left(\overline{\mathrm{x}}_{2}\right)\right\} \mathrm{G}^{\prime}(\mathrm{s})\right)$. At point $\mathrm{x}_{1}^{\prime}$, it can be shown that $\operatorname{Sign}\left(\left.\frac{\mathrm{dF}_{2}(\mathrm{~s})}{\mathrm{ds}}\right|_{\mathrm{x}_{1}^{\prime}}\right)=\operatorname{Sign}\left(\mathrm{C}^{\prime}\left(\mathrm{x}_{1}^{\prime}\right)-\mathrm{V}_{1} \mathrm{G}^{\prime}\left(\mathrm{x}_{1}^{\prime}\right)\right)=\operatorname{Sign}\left(-\left.\frac{\mathrm{dW}_{1}(\mathrm{~s})}{\mathrm{ds}}\right|_{\mathrm{x}_{1}^{\prime}}\right)<0$ as $\mathrm{W}_{1}($.$) is upward$ rising at point $\mathrm{x}_{1}^{\prime}$ (Claim 3 and Lemma 5). Thus $\mathrm{F}_{2}($.$) is decreasing at \mathrm{x}_{1}^{\prime}$ and consequently, there exists at least one minimum point of $\mathrm{F}_{2}($.$) in the open interval \left(\mathrm{x}_{1}^{\prime}, \overline{\mathrm{x}}_{2}\right)$.

Now, if we show that the minimum is unique then we will prove that (i) $F_{2}($.$) decreases from$ infinity to 1 at $\mathrm{x}_{1}^{\prime}$ and (ii) the minimum is in the interval $\left(\mathrm{x}_{1}^{\prime}, \overline{\mathrm{x}}_{2}\right)$. At a minimum, $\frac{\mathrm{dF}_{2}(\mathrm{~s})}{\mathrm{ds}}=0$, which implies $\frac{\left(\mathrm{G}(\mathrm{s}) \mathrm{C}^{\prime}(\mathrm{s})-\mathrm{C}(\mathrm{s}) \mathrm{G}^{\prime}(\mathrm{s})\right)}{\mathrm{G}^{\prime}(\mathrm{s})}=\mathrm{W}_{1}\left(\overline{\mathrm{x}}_{2}\right)$. Here RHS is a positive constant whereas LHS is an upward rising curve from origin. ${ }^{9}$ Thus there exists unique solution for $\frac{\left(G(s) C^{\prime}(s)-C(s) G^{\prime}(s)\right)}{G^{\prime}(s)}=W_{1}\left(\bar{x}_{2}\right)$, i.e., there exists unique minimum for $\mathrm{F}_{2}(\mathrm{.})$. Because $\mathrm{F}_{2}\left(\mathrm{x}_{1}^{\prime}\right)=\mathrm{F}_{2}\left(\overline{\mathrm{x}}_{2}\right)=1$ and $\mathrm{F}_{2}(\mathrm{~s})$ is decreasing at $\mathrm{x}_{1}^{\prime}, \therefore \operatorname{argmin}\left(\mathrm{F}_{2}(\mathrm{~s})\right)=\mathrm{x}_{2}^{\min } \in\left(\mathrm{x}_{1}^{\prime}, \overline{\mathrm{x}}_{2}\right)$.

These lemmas constitutes the shape of the NBFs that remain the basis of the equilibrium strategies.

${ }^{9}$ Note that $\left.\frac{\left(\mathrm{G}(\mathrm{s}) \mathrm{C}^{\prime}(\mathrm{s})-\mathrm{C}(\mathrm{s}) \mathrm{G}^{\prime}(\mathrm{s})\right)}{\mathrm{G}^{\prime}(\mathrm{s})}\right|_{0}=0$ and $\frac{\mathrm{d}\left[\left(\mathrm{G}(\mathrm{s}) \mathrm{C}^{\prime}(\mathrm{s})-\mathrm{C}(\mathrm{s}) \mathrm{G}^{\prime}(\mathrm{s})\right) / \mathrm{G}^{\prime}(\mathrm{s})\right]}{\mathrm{ds}}=\frac{\mathrm{G}(\mathrm{s})\left[\mathrm{G}^{\prime}(\mathrm{s}) \mathrm{C}^{\prime \prime}(\mathrm{s})-\mathrm{C}^{\prime}(\mathrm{s}) \mathrm{G}^{\prime \prime}(\mathrm{s})\right]}{\left[\mathrm{G}^{\prime}(\mathrm{s})\right]^{2}}>0$ 